\title{
Tocilizumab Significantly Decreases Reactive Oxygen Species Level in Patients with Rheumatoid Arthritis
}

\author{
Naoki Kondo ${ }^{*}$, Katsumitsu Arai'2, Takahiro Netsu' ${ }^{3}$, Tomotake Kanai', Hiroshige Sano1, \\ Go Okumura', Yasufumi Kijima ${ }^{1}$, Junichi Fujisawa1, Naoto Endo' ${ }^{1}$ \\ ${ }^{1}$ Division of Orthopaedic Surgery, Department of Regenerative and Transplant Medicine, Niigata University Graduate School of \\ Medical and Dental Sciences, Niigata, Japan \\ ${ }^{2}$ Division of Orthopaedic Surgery, Niigata Prefectural Chuo Hospital, Joetsu, Japan \\ ${ }^{3}$ Division of Rheumatology, Nagaoka Red Cross Hospital, Nagaoka, Japan \\ Email: *naokikondo1214@gmail.com
}

How to cite this paper: Kondo, N., Arai, K., Netsu, T., Kanai, T., Sano, H., Okumura, G., Kijima, Y., Fujisawa, J. and Endo, N. (2017) Tocilizumab Significantly Decreases Reactive Oxygen Species Level in Patients with Rheumatoid Arthritis. Open Journal of Rheumatology and Autoimmune Diseases, 7, 46-52.

https://doi.org/10.4236/ojra.2017.71004

Received: November 20, 2016

Accepted: January 8, 2017

Published: January 11, 2017

Copyright $\odot 2017$ by authors and Scientific Research Publishing Inc. This work is licensed under the Creative Commons Attribution International License (CC BY 4.0).

http://creativecommons.org/licenses/by/4.0/

\begin{abstract}
To determine the effect of tocilizumab (TCZ) on reactive oxygen species (ROS) in 11 patients with rheumatoid arthritis (RA), reactive oxygen metabolites (d-ROM) were measured using a Free Radical Elective Evaluator. The Disease Activity Score (DAS28) and matrix metalloproteinase-3 (MMP-3) level were also evaluated. d-ROM measured $392 \pm 110$ Carratelli units [U. CARR] on initiation of TCZ, and significantly decreased to $237 \pm 82,248 \pm$ 88 , and $226 \pm 91$ U.CARR after 3, 6, and 12 months, respectively ( $<0.05$ ). The DAS28-4-ESR was $4.77 \pm 1.0$ on initiation of TCZ, and significantly decreased to $2.19 \pm 1.23,1.51 \pm 0.71$, and $1.48 \pm 0.48$ after 3,6 , and 12 months, respectively ( $\mathrm{p}<0.05)$. Serum MMP-3 level was $197 \pm 150 \mathrm{ng} / \mathrm{ml}$ on initiation of TCZ, and was significantly decreased to $92 \pm 56,73 \pm 53$, and $69 \pm 41 \mathrm{ng} / \mathrm{ml}$ after 3, 6, and 12 months, respectively $(\mathrm{p}<0.05)$. Pearson analysis showed that d-ROM value was significantly correlated with DAS28 $(r=0.543, p<0.05)$, but not with MMP-3 $(r=0.174, p=0.29)$. TCZ was found to rapidly and significantly decrease ROS in patients with RA, and d-ROM value may be useful as a marker of disease activity of RA.
\end{abstract}

\section{Keywords}

Tocilizumab, Rheumatoid Arthritis, Reactive Oxygen Species, Disease Activity Score 28

\section{Introduction}

Rheumatoid arthritis (RA) is an autoimmune disease characterized by diffuse 
synovitis. Inflammatory infiltrates accumulate and persist in synovial membranes, and the clinical presentation is dominated by destruction of joint architecture [1] [2].

Reactive oxygen species (ROS) such as superoxide radicals, hydrogen peroxide, hydroxyl radicals, and hypochlorous acid are produced in inflamed joints in RA [1] [3].

Tumor necrosis factor inhibitors such as infliximab and etanercept downregulate oxidative stress markers such as urinary 8-hydroxydeoxyguanosine in patients with RA [4] [5].

$\mathrm{NF}-\kappa \mathrm{B}$ is reportedly a major regulator of ROS generation in leukemia cell lines [6]. However, the inhibitory mechanism of interleukin-6 (IL-6) in ROS generation remains unknown.

It is difficult to measure and monitor ROS in vivo because these substances are rapidly metabolized. A simple test for d-reactive oxygen metabolites (d-ROM) has been developed and is able to detect the total amount of ROS in the body [7]. Previous reports demonstrated that d-ROM values in RA patients were significantly higher than those in osteoarthritis patients [8], and that d-ROM levels are significantly correlated with disease activity in RA [9].

Then, the effect of tocilizumab (TCZ), an anti-IL-6 receptor antibody on dROM value in patients with RA was examined. The results in the current study demonstrated that TCZ significantly and rapidly downregulates ROS in serum of RA patients, with associated improvement of disease activity.

\section{Materials and Methods}

\subsection{Patients and Blood Samples}

Eleven RA patients were recruited to this study. Patients with comorbidities such as diabetes mellitus, chronic kidney diseases more than grade 3, and chronic obstructive pulmonary disease (COPD) were excluded. RA patients who met the 1987 American College of Rheumatology diagnostic criteria [10] were recruited. TCZ was administered to all patients according to the guidelines of the Japan College of Rheumatology, and was continued for at least 1 year. Detailed data are shown in Table 1 . The average age was $54 \pm 17$ years (range $16-70 ; 4$ males and 7 females). Steinbrocker Stage was II, III, and IV in 1, 5, and 5 cases, respectively. Steinbrocker Class was 2, 3, and 4 in 5, 4, and 2 cases, respectively. RA disease duration was $12 \pm 13$ years on average $(0.2-37)$. There were 8 biologic-naive cases. Biologics had been used in 3 cases prior to TCZ, and included etanercept, infliximab and adalimumab, and adalimumab, respectively. Methotrexate had been used in 6 cases at an average dose of $4.2 \pm 4.0 \mathrm{mg} /$ week $(0-8 \mathrm{mg} /$ week). Methylprednisolone had been used in 7 cases at an average dose of $3.4 \pm 3.0$ $\mathrm{mg} /$ day ( 0 - $7 \mathrm{mg} /$ day). The patients were registered from September 2009 to July 2012 and the study period to collect each data was determined to 12 months.

This observational study began after approval by the Institutional Review Board at Niigata University School of Medicine (ID number 1345) and had obtained ethical clearance. Informed consent was achieved for all the registered 
Table 1. Demographic data. Abbreviations: ETN, etanercept; IFX, infliximab; ADA, adalimumab; MTX, methotrexate; PSL, prednisolone.

\begin{tabular}{|c|c|c|c|c|c|c|c|c|}
\hline \multirow{2}{*}{ Case } & \multirow{2}{*}{ Age } & \multirow{2}{*}{ Gender } & \multicolumn{2}{|c|}{ Steinbrocker } & \multirow{2}{*}{$\begin{array}{c}\text { RA disease } \\
\text { duration (yrs) }\end{array}$} & \multirow{2}{*}{$\begin{array}{c}\text { Previously } \\
\text { used biologics }\end{array}$} & \multirow{2}{*}{$\begin{array}{c}\text { MTX } \\
\text { (mg/week) }\end{array}$} & \multirow{2}{*}{$\begin{array}{c}\text { PSL } \\
\text { (mg/day) }\end{array}$} \\
\hline & & & Stage & Class & & & & \\
\hline 1 & 70 & $\mathrm{~F}$ & IV & 4 & 9.6 & Naïve & 8 & 6 \\
\hline 2 & 65 & $\mathrm{~F}$ & IV & 3 & 33.0 & Naïve & 0 & 7 \\
\hline 3 & 57 & M & III & 2 & 8.5 & ETN & 8 & 7 \\
\hline 4 & 59 & M & III & 2 & 5.0 & Naïve & 8 & 5 \\
\hline 5 & 51 & $\mathrm{~F}$ & III & 2 & 0.5 & Naïve & 0 & 2.5 \\
\hline 6 & 35 & M & II & 2 & 0.2 & Naïve & 8 & 5 \\
\hline 7 & 68 & M & III & 3 & 1.6 & Naïve & 6 & 0 \\
\hline 8 & 16 & $\mathrm{~F}$ & III & 2 & 1.2 & Naïve & 0 & 0 \\
\hline 9 & 43 & $\mathrm{~F}$ & IV & 3 & 21.5 & Naïve & 0 & 0 \\
\hline 10 & 68 & $\mathrm{~F}$ & IV & 4 & 12.5 & IFX, ADA & 0 & 5 \\
\hline 11 & 60 & $\mathrm{~F}$ & IV & 3 & 37.0 & $\mathrm{ADA}$ & 8 & 0 \\
\hline
\end{tabular}

patients. Blood sampling was performed on day 0 (immediately before initial TCZ treatment), and 3, 6, and 12 months later. Erythrocyte sedimentation rate (ESR) and serum matrix metalloproteinase-3 (MMP-3) levels were measured at each time point. Disease Activity Score (DAS28-4-ESR) was determined by tender and swollen joint counts and the visual analogue scale (VAS) on visits to the outpatient clinic.

\subsection{Measurement of Oxidative Stress Markers in Serum}

Venous blood samples were collected at each time point and serum oxidative stress markers were measured.

A Free Radical Elective Evaluator (FREE) (Diacron, Italy) was used according to the manufacturer's protocol. A 20- $\mu \mathrm{l}$ serum sample was added to $1 \mathrm{ml}$ of buffered solution (R2 reagent kit), and $20 \mu \mathrm{l}$ of chromogenic substrate (R1 reagent kit) was added to the cuvette. After mixing, the sample was immediately incubated in the thermostatic block of the analyzer for $5 \mathrm{~min}$ at $37^{\circ} \mathrm{C}$. Absorbance was recorded at $505 \mathrm{~nm}$. The measurement was recorded as Carratelli units (U.CARR; 1 U.CARR corresponds to $0.08 \mathrm{mg} / \mathrm{dl}_{2} \mathrm{H}_{2}$ ). Reference values suggested by the manufacturer are $<300$ U.CARR. Values were defined for d-ROM; more than 300 U.CARR suggests high oxidative stress.

\subsection{Statistical Analysis}

All statistical analysis was performed using SPSS (Ver. 21) software (IBM, Chicago, IL, USA). P-values less than 0.05 were considered significant.

Paired t-tests were performed for each parameter (DAS28, d-ROM, MMP-3).

Pearson's correlation coefficient test was used for parametric data.

\section{Results}

The DAS28-4-ESR score was $4.77 \pm 1.0$ at initiation of TCZ, and significantly 
decreased to $2.19 \pm 1.23,1.51 \pm 0.71$, and $1.48 \pm 0.48$ after 3,6 , and 12 months, respectively, $(\mathrm{p}<0.05)$ (Figure $1(\mathrm{a})$ ).

d-ROM was $392 \pm 110$ U.CARR at initiation of TCZ, and significantly decreased to $237 \pm 82,248 \pm 88$, and $226 \pm 91$ U.CARR after 3, 6, and 12 months, respectively $(\mathrm{p}<0.05)$ (Figure $1(\mathrm{~b})$ ). All average U.CARR values at 3, 6, and 12 months were below 300 , indicating normal oxidative stress states.

Serum MMP-3 level was $197 \pm 150 \mathrm{ng} / \mathrm{ml}$ at initiation of TCZ, and was significantly decreased to $92 \pm 56,73 \pm 53$, and $69 \pm 41 \mathrm{ng} / \mathrm{ml}$ after 3,6, and 12 months, respectively $\quad(\mathrm{p}<0.05)$ (Figure $1(\mathrm{c})$ ).

Pearson analysis showed that $\mathrm{d}-\mathrm{ROM}$ value was significantly correlated with DAS28 $(r=0.543, \mathrm{p}<0.05)$, but not with MMP-3 $(\mathrm{r}=0.174, \mathrm{p}=0.29)($ Table 2$)$.

\section{Discussion}

In patients with RA, serum oxidative stress markers are significantly upregulated [11]. In cultured synovial cells, antioxidants reduce tumor necrosis factor alpha (TNF-alpha)-mediated stimulation of some inflammatory cytokines [12].

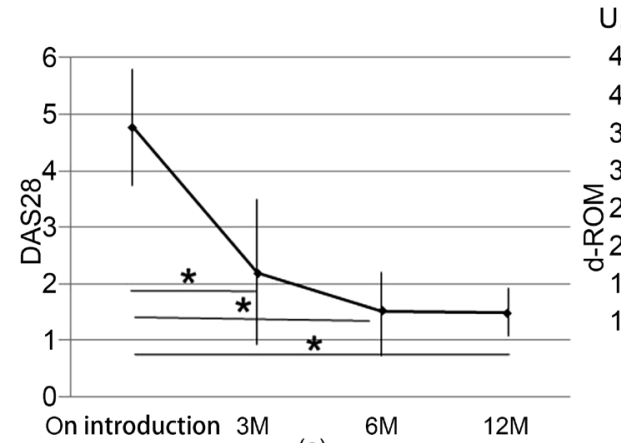

(a)
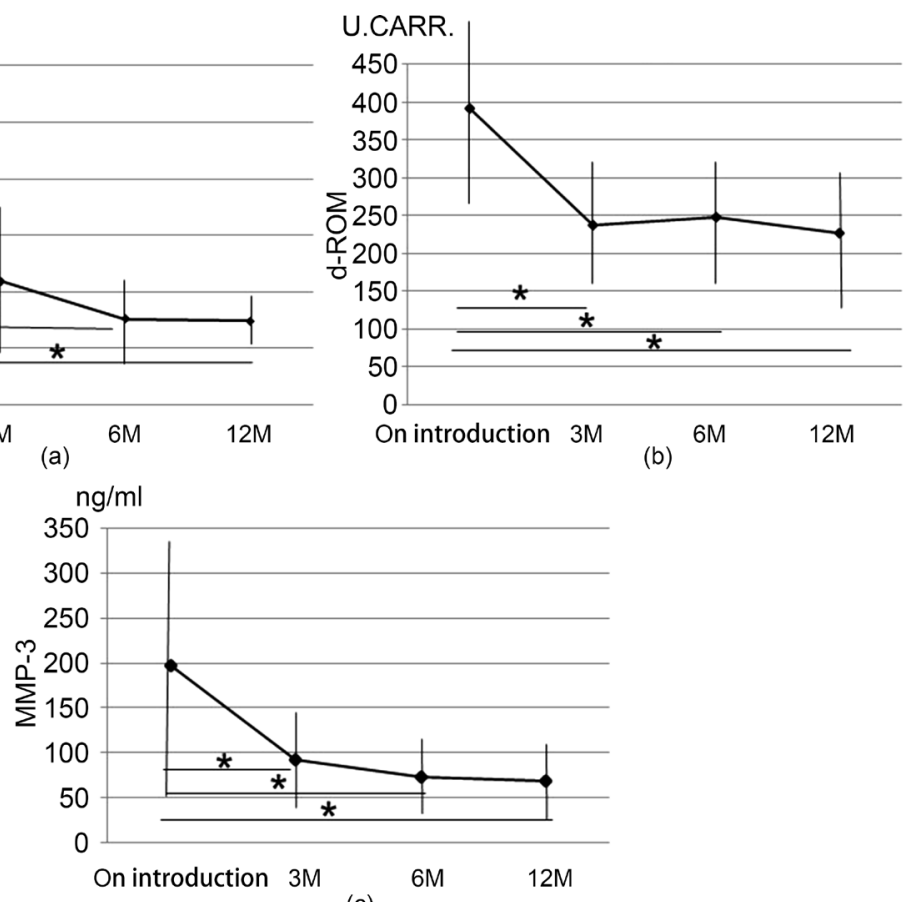

(c)

Figure 1. (a) Change in disease activity score after initiation of tocilizumab (TCZ). (b) Change in d-ROM (reactive oxygen metabolites) after initiation of TCZ. (c) Change in serum MMP-3 after initiation of TCZ. ${ }^{*}, \mathrm{p}<0.05$.

Table 2. Correlation between d-ROM value and DAS28 or serum MMP-3. ${ }^{*}, \mathrm{p}<0.05$.

\begin{tabular}{cc}
\hline & $r$ (Peason's correlation coefficient) \\
\hline DAS28 & $0.543^{*}$ \\
MMP-3 & 0.174 \\
\hline
\end{tabular}

${ }^{*} \mathrm{p}<0.05$. 
In our previous study, serum ROM values were high (525 U.CARR on average, at baseline), and decreased to 366 U.CARR on average in the final observation period with use of biologics in patients with RA. Simultaneously, DAS28-3-CRP, C-reactive protein (CRP), ESR, and MMP-3 were also decreased. However, in refractory RA cases, d-ROM values were never downregulated [13].

In addition, we also previously reported that etanercept (ETN) prospectively reduced d-ROM values from 393 U.CARR at initiation to 337 U.CARR at 12 months after etanercept treatment. DAS28 score also improved from 4.69 at initiation to 2.60 at 12 months after etanercept treatment [14]. This result was in accordance with that in a previous report [4]. In the current study, we examined whether TCZ decreased serum levels of oxidative stress markers in association with DAS28 improvement in a time-dependent manner.

To the best of our knowledge, this is the first report that TCZ prospectively downregulates ROS levels in patients with RA. Furthermore, the antioxidative effect of TCZ may be more prominent that that of ETN.

The d-ROM value showed the highest correlation with MMP-3 $(\mathrm{r}=0.637, \mathrm{p}<$ $0.001)$, followed by CRP $(r=0.558, p<0.001)$, ESR $(r=0.486, p<0.01)$, and DAS28-4-ESR $(r=0.352, p<0.05)$ [14]. In the current study, $d-R O M$ value had a high correlation with DAS28, but no significant correlation was detected with MMP-3. The reason for this difference remains unknown. However, a significant correlation was detected in RA patients treated with TCZ, similar to that with ETN. Therefore, d-ROM values can be good surrogate markers of disease activity in RA.

In an evaluation of $152 \mathrm{RA}$ patients, d-ROM values were significantly positively correlated with CRP, MMP-3, DAS28-ESR, the Clinical Disease Activity Index, and the Simplified Disease Activity Index [9].

Hirao et al. previously reported an average d-ROM value of 239.2 U.CARR in RA patients treated with TCZ, which was lower than the value in those treated with disease modifying antirheumatic drugs (464.2 U.CARR) and controls (osteoarthritis cases) (375.5 U.CARR). However, this evaluation was performed at only a single time point. In our study, patients were prospectively followed, and patients with comorbid diabetes mellitus, chronic kidney disease more than grade 3 , and chronic obstructive pulmonary disease (COPD) were excluded, because these comorbidities permanently and endogenously upregulate oxidative stress markers. Therefore, our study may provide better evidence than previous reports [8] [9].

There were some limitations in our study. First, only 11 cases were evaluated, and the small number reduces the statistical power. Second, comparison was not performed using other biologics such as TNF inhibitors. Third, the mechanism by which IL-6 inhibitory transactions downregulate ROS remains unknown.

Further examination of the pathways involved in signal transduction is important, and the key molecules involved in ROS downregulation by TCZ should be identified. 


\section{Conclusion}

In summary, TCZ rapidly and significantly decreased ROS in patients with RA and d-ROM value in sera may be a useful marker of disease activity of RA.

\section{Acknowledgements}

We would like to thank Editage (www.editage.jp) for English language editing.

\section{References}

[1] Bauerova, K. and Bezek, S. (1999) Role of Reactive Oxygen and Nitrogen Species in Etiopathogenesis of Rheumatoid Arthritis. General Physiology and Biophysics, 18, 15-20.

[2] Weyand, C.M. and Goronzy, J.J. (1997) The Molecular Basis of Rheumatoid Arthritis. Journal of Molecular Medicine, 75, 772-785. https://doi.org/10.1007/s001090050167

[3] Biemond, P., Swaak, A.J. and Koster, J.F. (1984) Protective Factors against Oxygen Free Radicals and Hydrogen Peroxide in Rheumatoid Arthritis Synovial Fluid. Arthritis \& Rheumatology, 27, 760-765. https://doi.org/10.1002/art.1780270706

[4] Kageyama, Y., Takahashi, M., Nagafusa, T., Torikai, E. and Nagano, A. (2008) Etanercept Reduces the Oxidative Stress Marker Levels in Patients with Rheumatoid Arthritis. Rheumatology International, 28, 245-251.

https://doi.org/10.1007/s00296-007-0419-1

[5] Kageyama, Y., Takahashi, M., Ichikawa, T., Torikai, E. and Nagano, A. (2008) Reduction of Oxidative Stress Marker Levels of Anti-TNF- $\alpha$ Antibody, Infliximab, in Patients with Rheumatoid Arthritis. Clinical and Experimental Rheumatology, 26, 73-80.

[6] Moon, D., Kim, M.O., Kang, S.H., Choi, Y.H. and Kim, G.Y. (2009) Sulforaphane Suppresses TNF-Alpha-Mediated Activation of NF-Kappa B and Induces Apoptosis through Activation of Reactive Oxygen Species-Dependent Caspase-3. Cancer Letters, 274, 132-142. https://doi.org/10.1016/j.canlet.2008.09.013

[7] Cesarone. M.R., Belcaro, G., Carattelli, M., Cornelli, U., De Sanctis, M.T., Incandela, L., Barsotti, A., Terranova, R. and Nicolaides, A. (1999) A Simple Test to Monitor Oxidative Stress. International Angiology, 18, 127-130.

[8] Hirao, M., Yamasaki, N., Oze, H., Ebina, K., Nampei, A., Kawato, Y., Shi, K., Yoshikawa, H., Nishimoto, N. and Hashimoto, J. (2012) Serum Level of Oxidative Stress Marker Is Dramatically Low in Patients with Rheumatoid Arthritis Treated with Tocilizumab. Rheumatology International, 32, 4041-4045.

https://doi.org/10.1007/s00296-011-2135-0

[9] Nakajima, A., Aoki, Y., Shibata, Y., Sonobe, M., Terajima, F., Takahashi, H., Saito, M., Taniguchi, S., Yamada, M. and Nakagawa, K. (2014) Identification of Clinical Parameters Associated with Serum Oxidative Stress in Patients with Rheumatoid Arthritis. Modern Rheumatology, 24, 926-930. https://doi.org/10.3109/14397595.2014.891495

[10] Arnett, F.C., Edworthy, S.M., Bloch, D.A., McShane, D.J., Fries, J.F., Cooper, N.S., Healey, L.S., Kaplan, S.R., Liang, M.H. and Luthra, H.S. (1988) The American Rheumatism Association 1987 Revised Criteria for the Classification of Rheumatoid Arthritis. Arthritis \& Rheumatology, 31, 315-324. https://doi.org/10.1002/art.1780310302

[11] Datta, S., Kundu, S., Ghosh, P., De, S., Ghosh, A. and Chatterjee, M. (2014) Correla- 
tion of Oxidant Status with Oxidative Tissue Damage in Patients with Rheumatoid Arthritis. Clinical Rheumatology, 33, 1557-1564.

https://doi.org/10.1007/s10067-014-2597-Z

[12] Sato, M., Miyazaki, T., Nagaya, T., Murata, Y., Ida, N., Maeda, K. and Seo, H. (1996) Antioxidants Inhibit Tumor Necrosis Factor- $\alpha$ Mediated Stimulation of Interleukin-8, Monocyte Chemoattractant Protein-1, and Collagenase Expression in Cultured Human Synovial Cells. The Journal of Rheumatology, 23, 432-438.

[13] Netsu, T., Kondo, N., Arai, K., Fujisawa, J. and Endo, N. (2013) The Serum Oxidative Stress Values before and after Treatment of Biologics in Patients with Rheumatoid Arthritis. Archives of Niigata Society of Orthopaedic Surgery, 29, 37-40. (In Japanese)

[14] Yamanaka., K., Kondo, N., Arai, K., Fujisawa, J., Netsu, T. and Endo, N. (2013) Etanercept Decreases Serum Oxidative Stress in Patients with Rheumatoid Arthritis. Archives of Niigata Society of Orthopaedic Surgery, 29, 73-76. (In Japanese)

Submit or recommend next manuscript to SCIRP and we will provide best service for you:

Accepting pre-submission inquiries through Email, Facebook, LinkedIn, Twitter, etc. A wide selection of journals (inclusive of 9 subjects, more than 200 journals)

Providing 24-hour high-quality service

User-friendly online submission system

Fair and swift peer-review system

Efficient typesetting and proofreading procedure

Display of the result of downloads and visits, as well as the number of cited articles

Maximum dissemination of your research work

Submit your manuscript at: http://papersubmission.scirp.org/

Or contact ojra@scirp.org 